\title{
Network Structures in the International Clothing Industry
}

\author{
B.L. MacCarthy and P.G.S.A. Jayarathne \\ Nottingham University Business School, \\ Jubilee Campus, Nottingham, NG8 1BB, UK \\ bart.maccarthy@nottingham.ac.uk
}

\begin{abstract}
The structure and operation of supply networks have received considerable attention from both the business community and academic researchers in the last two decades as the pace of globalisation has accelerated. Supply networks in the international clothing industry have developed and evolved significantly over that period. This paper reviews different ways to categorise supply networks and notes their limitations in providing insights on the structure and operation of networks in the contemporary global clothing industry. Leading retailers and major clothing brand owners influence strongly how such networks operate. Given the limitations of existing generic classifications, a new classification of clothing supply networks is presented based on extensive empirical evidence from the Sri Lankan clothing industry. The relevance of the findings for network design and management are noted. This study of supply networks in the international clothing industry provides much potential for further research, particularly in globally dispersed industries.
\end{abstract}

Keywords: goal-oriented supply network structures, global clothing industry, classification.

\section{Introduction}

The structure and management of supply networks have received considerable attention from both the business community and academic researchers in the last two decades as the pace of globalisation has accelerated and supply networks have become increasingly globally dispersed. The clothing industry is known to be one of the most global, mobile and dynamic industries in the world [20] and contributes significantly to the world economy. The international export trade in clothing increased by over $100 \%$ in the period $1990-2003$ [27].

Over the last two decades, complex global supply networks have emerged to supply garments to world markets with different network structures, strategies and practices. Although different ways of categorizing supply networks have been discussed in the literature, they are very limited in providing insights on global apparel supply networks. International clothing supply networks are driven primarily by retailers that exert significant power and control. The work presented here is part of a study that seeks to (1)identify the different supply network structures that operate in the international clothing industry and (2) examine how such structures are developed and managed according to the goals of different retailers. 
The paper first provides a brief overview of different ways of categorizing supply networks from the existing literature, highlighting some of their limitations. Then, the nature of international clothing supply networks and the role of retailers within such networks are discussed. A case study of a major supply network is used to illustrate the complexity of such networks and the influence of retailer goals on network structure, policies and operation. A new way of classifying networks is described. The differences between the supply networks of major reputable retailers and supermarket clothing retailers are highlighted.

\section{Supply Network Structures}

The term 'supply network' has been defined in different ways. Harland (1996) defines it as a set of supply chains describing the flow of goods and services from original sources to end customers [11]. Harland and Knight (2001) define a supply network as a system comprising of actors, resources and activities and their connections related to transforming inputs into products and services [12]. Harland et al. (2004) describe supply networks as being nested within wider inter-organizational networks and consisting of inter-connected entities whose primary purpose is the procurement, use and transformation of resources to provide packages of goods and services [13]. Christopher (2005) defines a supply network as "a network of connected and interdependent organizations mutually and co-operatively working together to control, manage and improve the flow of materials and information from suppliers to end users" [3]. Here we use the definition given by Harland and Knight (2001).

Different perspectives have been used to classify supply networks. Hinterhuber and Levin (1994) have categorized networks into four classes with respect to direction and network orientation - internal, vertical, horizontal and diagonal [15]. Some 'vertical' networks operate in the clothing industry. For instance, Zara manages its globally dispersed supply networks as essentially a vertically integrated network. However, not all apparel supply networks operate in a 'vertical' mode [19]. Cravens et al (1996) categorize supply networks into four clusters - flexible, hollow, virtual, and valueadded. Although 'flexible' and 'virtual' networks may appear in apparel networks, one can be contained in the other [4]. In particular, virtual networks provide a strategic perspective in which a flexible network can operate at the operational level.

Nassimbeni (1998) identifies three main supply network categories - 'supply network', 'agreements and joint ventures', and 'regional industrial systems' [21]. However, many different types of clothing supply networks can be put into one category 'supply networks'. Lamming et al. (2000) categorize supply networks based on two dimensions - product innovation and uniqueness ('innovative-unique' products against 'functional' products), and product complexity (high against low) [17]. However, such categories do not discriminate well between different clothing products, as will be noted later. Ernst and Kamrad (2000) identify four types of supply networks rigid, flexible, modularized and postponed [6]. Among these, only 'flexible' and 'postponed' structures have clear implications for the apparel industry and not all clothing networks can be categorized into these two types.

Harland et al. in 2001 discuss four types of supply networks based on two dimensions - whether they are routinized or dynamic and the degree of influence of the 
focal firm (high or low) [14]. This classification is empirically based and, compared to other classifications, provides more detail on operational strategies of relevance in the apparel industry. However, the identification of the 'focal firm' may be problematic in applying this classification. Lee (2002) classifies supply network types into four, based on their supply and demand characteristics and the strategy that should be deployed - efficient supply chains, risk-hedging supply chains, responsive supply chains, and agile supply chains [18]. Almost all clothing supply networks need to be responsive in today's world. Hence, sub categories within the responsive category need to be identified with relevance to the apparel industry.

Verwaal and Hesselmas (2004) use two dimensions in their classification of supply networks - interdependence of organizational activities and asset specificity [29]. They identify two network types - 'equal-partner network' and 'dominated network' International clothing supply networks can be identified as dominated networks as they are typically controlled by powerful retailers. However, although this is generally true, the way retailers exercise their power differs depending on their goals. This is discussed further in section 5 below.

Other supply network classification perspectives reported include: whether the network is formalized or not and whether it is centralized or parity-based [10]; different types of industrial clusters [22]; hard and soft networks [23]; and a classification based on manufacturing flexibility characteristics [8].

Most of the identified classifications are very general and fail to discriminate clearly or provide significant explanatory power when examining the detailed structure and operation of many real supply networks. In particular they are weak in explaining the nature and characteristics of supply networks in the contemporary international clothing industry. This paper presents a new approach to the classification of supply networks in this sector.

\section{International Clothing Supply Networks}

\subsection{The Global Clothing Industry}

The global clothing industry is important for both developed and developing countries. For instance, the apparel industry in Sri Lanka is the main foreign exchange income source, contributing $56 \%$ of its industrial export income and $43 \%$ of its total export income in 2008 [2]. In the EU, over 2 million people were employed in the textile and apparel industry in 2006 (Euratex, 2006 - cited from [5]). In the US, the sector currently employs over four hundred thousand workers [28].

Although the US and the EU are major clothing markets, apparel manufacturing has migrated in the last three decades to newly industrialized countries, developing countries and under-developed countries [27]. Deregulation and the abolition of quotas, in particular abolition of the Multi Fibre Agreement (MFA) at the end of 2004 has accelerated the mobility of this industry. Some countries have benefited whilst others have lost out. China and India have shown very strong growth after 2004 [1]. However, Sri Lanka with a long tradition of apparel manufacturing has seen its clothing industry decline from $71 \%$ of its total industrial exports in 2004 to $56 \%$ in 2008 [2] 
with the abolition of the MFA. These phenomena are important in understanding the types of supply networks that have emerged in the international clothing industry.

\subsection{Retailer-Driven International Clothing Supply Networks}

In addition to the dispersal of clothing manufacturing activities, the industry has changed tremendously during the last two decades owing to the dynamics in apparel demand and supply. Today's apparel demand is more fragmented with an increasing fashion influence across all product categories [16]. Both product variety and new product introduction have been accelerating in 'basic garments' as well as 'fashion garments' [24]. A fashion element has now developed in many 'basic garments', typically classed as volume or commodity products [19], [24], [25]. Traditional apparel markets with two fixed seasons per year have given way to frequent refreshes within a season. Competitive retailers focus on replenishment of the specific styles, designs and colours that are selling well, whilst reducing or abandoning those that turn out to be less popular than forecast [7], [19], [25]. Importantly, the trends of compressing new product introduction time, multiple refreshes per season and very quick response from suppliers, need to be achieved at low cost [19], [25].

Retailers and major brand owners are the most powerful players in the apparel supply network. Gereffi (1999) and Tyler et al (2006) highlight how current international clothing supply networks are buyer-driven in contrast to producer-driven supply networks [9], [26]. Gereffi (1999) notes that buyer-driven clothing supply networks are often characterized by loose and dynamic couplings linking production mainly in developing countries with fashion demand in developed countries [9]. Hence, they rely on global sourcing strategies to meet demand. Profit is generated from design, sales, marketing and services that link globally spread production plants with consumer markets [26].

Apparel supply networks may contain many entities including designers, merchandisers, yarn producers, fabric producers, trims producers, garment manufacturers, distributors, logistics and warehouse companies, and retailers [30]. Retailers use different supply network members to cope with dynamic demand in apparel markets. Further, because of raw material and capacity availability, cost advantages, and other factors such as trade policies, clothing supply networks tend to be dispersed internationally and may become highly complex, long and heterogeneous.

Most of the powerful apparel retailers are based in the developed countries mainly in the US and in EU. Some of these retailers are noted brand owners (e.g. M\&S, Next, Zara, Nike, Victoria Secret) whilst others are supermarket brands (e.g.: Asda, Tesco, Sainsbury, and Wal-Mart). In the UK, the supermarket brands now account for a significant proportion of the apparel sales per year. Apparel manufacturers in developing countries supply both types of retailers. A question considered here is whether these two types of apparel retailer use different supply networks and whether they operate them differently.

The Sri Lankan clothing industry has evolved during the last three decades as the most important industrial sector in the economy in terms of production, employment, and foreign income generation. It has developed a reputation as a niche supplier of intimate apparel. Sri Lankan apparel manufacturers supply high quality value-added garments to leading retailers in EU and in the USA, including many well known 
international brands such as Gap, Liz, Claiborne, Next, Tommy Hilfiger, Victoria Secrets, Nike, and M \& S [27]. They also supply garments for supermarket brands such as Asda, Tesco, and Wal-Mart. Thus Sri Lanka provides an opportunity to examine different types of clothing supply networks and how they operate in the global context.

\section{Methodology}

The goal of the work is to understand the structure, operation and policies of different supply networks in the international clothing industry. The field work for this research has been conducted in a non-contrived setting - the Sri Lankan apparel industry. The unit of analysis is a specific apparel supply network. Several research methods and data collection instruments have been used. Both primary and secondary data have been collected. The study was cross-sectional in the time horizon as data have been collected over a specific period of time.

Thirty case companies were selected from the Sri Lankan apparel industry, including all of the major producers in the country, each of which has significant manufacturing networks. In-depth interviews were carried out with strategic and operational level managers to gain detailed information on the structure and operation of different supply networks. Strategic level managers were interviewed to investigate the goals, motives and policies of different retailers. Typically such managers had worked closely with retailers for a long time. Operational level managers were interviewed to investigate the operational aspects of the supply networks. In addition, observations were made by the researcher on each organisation to add to the primary data. Interviews were also conducted with relevant government bodies and agencies to provide context and understanding of the international dimensions of the industry.

Secondary data sources used include literature resources, reports and publications from government authorities and from selected apparel manufacturers. Together the different sources have provided rich information for analysis and mapping of a large number of supply networks. The multiple methods and sources used, including indepth interviews, company documents, government publications and observations, have enabled triangulation of research findings to increase validity and reliability.

\section{Findings and Discussion}

We illustrate the complexity of international supply networks in clothing and the need for a new classification scheme with an example from the field work.

\subsection{Case Study}

Company SLX (note: company identities have been anonymised) is a leading established Sri Lankan apparel company and a major supplier to a range of well known retailers, garment brand owners and supermarkets including $M \& S$, Tommy Hilfiger, Liz Claiborne, Nike, Victoria's Secret, Polo, Bhs, Tesco and Asda. As a group its overall manufacturing capacity is in excess of 3 million garments per month. It has 
three main local manufacturing clusters including woven and knit and maintains strategic alliances with international factories in Bangladesh and Vietnam. Currently it operates with an integrated manufacturing structure that includes factories, designing capabilities, product development, printing, embroidery and washing facilities. SLX's entire network, including the major material and information flows and quality processes of for all its customers, is highly complex. Space limitations preclude us depicting the entire network here. Figures 1 and 2 illustrate how Company SLX operates for two different types of retailer.

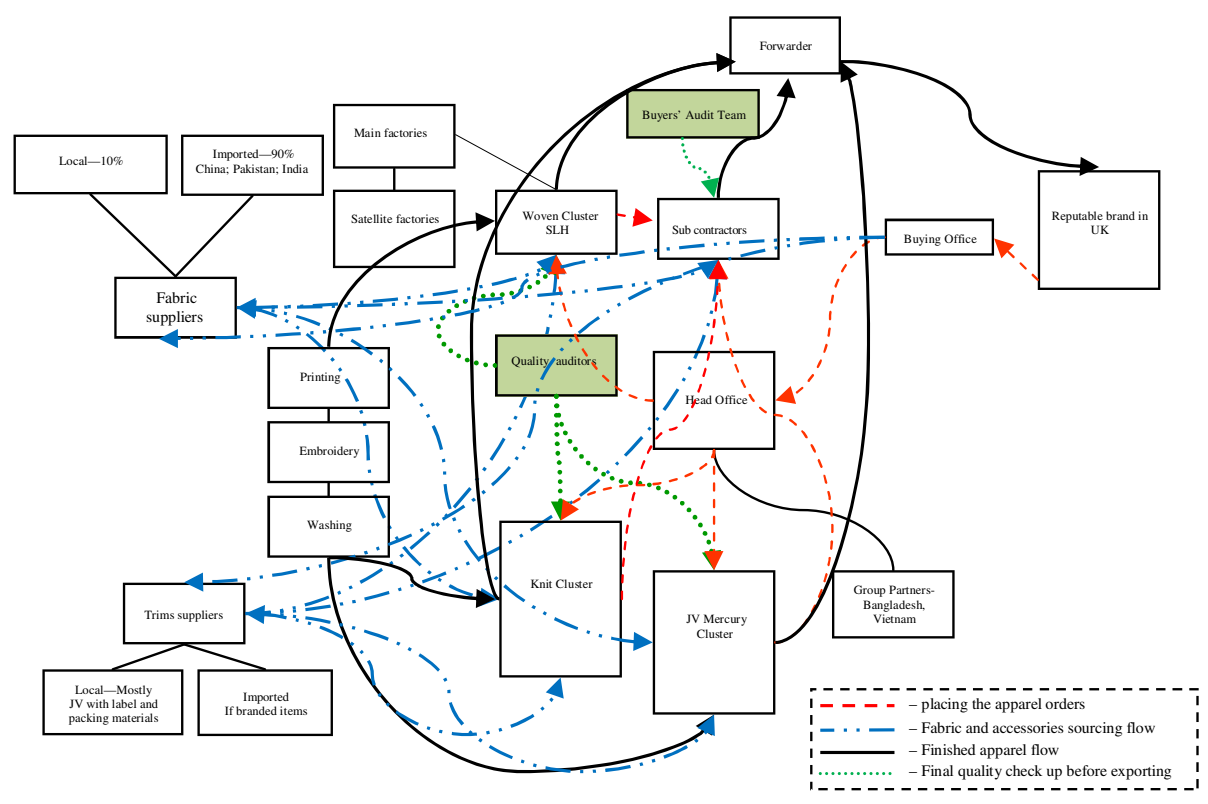

Fig. 1. Supply Network for a Leading Retailer

Figure 1 depicts the supply network for a leading retailer producing both simple and complicated garments. The retailer designs the styles using the services of garment designers and fashion houses. They then request the manufacturer to develop samples accordingly. Once the samples are approved by the buying team at the retailer they place orders with agreed colours, volume, sizes, delivery dates, etc (note: sample development consists of several steps not discussed in this paper). These orders are then placed with an appropriate production cluster according to the request of the retailer or its agent while considering the cluster's competency. It is important to note that fabric and accessory sourcing decisions including material specification and supplier selection are done mostly on the recommendation of the retailer or its buying office. Mostly, the retailer has already developed the fabrics at the product development stage itself. Sometimes the retailer may place only part of the order in Sri Lanka, placing the rest in another country to minimize risk. In that case, all the suppliers, including those in Sri Lanka, need to source from the same fabric suppliers to maintain quality and consistency. The agent of the retailer closely monitors the entire 
process in order to ensure garments are produced according to their standards and on time. Then, a final quality audit is carried out mostly by the buyer appointed by quality auditors collaborating with the buying office. Finally, the approved garments are first sent to the buyer's stores in Sri Lanka and then exported to the retail stores via a forwarding company recommended by the retailer.

Figure 2 depicts the supply network of a major supermarket. Unlike the network in Figure 1, the design is a more collaborative activity with the supplier. The manufacturer may design the garments alone and present them as 'story boards' from which the buying team at the supermarket selects certain designs and then proceeds with sample development. Garment designers are employed in the company for such designing purposes. Sometimes the manufacturers provide the design or the supermarket may provide ideas or samples for the manufacturer to develop a design. In such cases, a supermarket may use the service of garment designers. After sample approval, orders are placed including details of colours, volume, sizes, delivery dates, etc. These orders are then placed to the respective cluster according to their production competency. Fabric and accessory sourcing decisions including material specification and supplier selection are mostly made by the respective production clusters, unlike the case of a leading retailer's network. The company needs to get the quality of all fabric and accessories approved by the supermarket in advance and then they can source from any suppliers that provide such approved standards. The final quality audit is also carried out by the manufacturing company itself. Finally, the approved garments are first sent to the stores of such supermarket brands in Sri Lanka and then exported to the buyer via the forwarder recommended by the supermarket retailer.

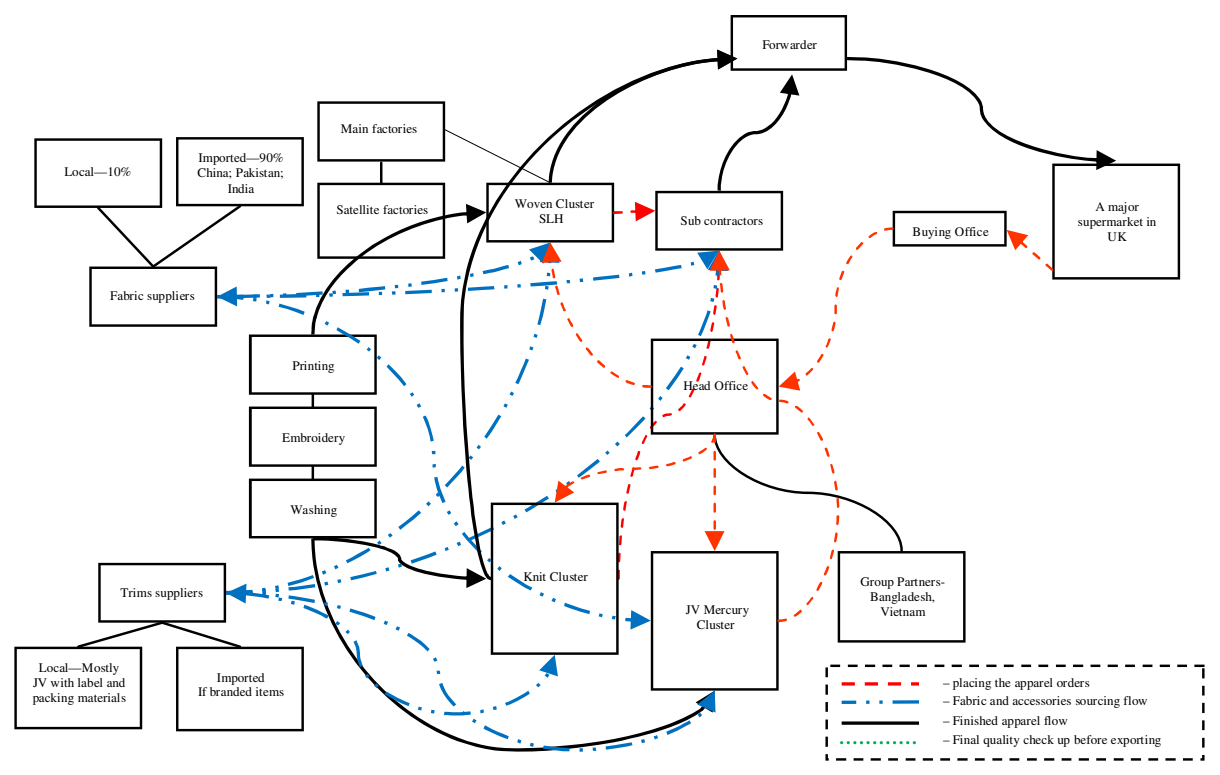

Fig. 2. Supply Network for a Major Supermarket 


\subsection{A New Classification for Supply Networks in the International Clothing Industry}

As noted earlier the supply network categorizations in the literature provide only limited insights into the structure and operation of international clothing supply networks. Based on an analysis across all the thirty case companies studied in this research, a new classification is being developed from the retailer's perspective (including both the leading retailers and supermarkets). The perspective of the new scheme is to provide insights into how the apparel retailer governs the supply to meet anticipated demand from their customers. The principles of this classification are described briefly here. The classification is based on four dimensions:

1. Direct or indirect retailer control: considers whether retailers use agents (buying offices) as intermediaries when dealing with manufacturers or whether they deal directly with manufacturers.

2. Control of sourcing: considers which entity controls the sourcing of fabrics and in some cases trims - the retailer, the manufacturer or through collaborative sourcing. Fabric sourcing practices have mainly been considered as it is the most important sourcing decision in garment production.

3. Garment complexity: two types of garments are considered - complicated designs and simple designs. Garments with complicated structures and/or embellishments (e.g. embroidery, washing) are considered as complicated designs whereas garments with basic structures and/or without embellishments are simple designs. This dimension is more specifically relevant to the contemporary apparel industry than a 'functional' or 'innovative' product differentiation as advocated in some generic classifications.

4. Direct or indirect retailer involvement in quality assurance: this relates to the presence or absence of a retailer's involvement in the final quality assurance procedures.

These four dimensions have been derived from a two stage analysis. Initially the dimensions used in literature classifications were analysed to examine their applicability to contemporary clothing supply networks. The results showed that none could be applied to generate strong insights on the observed networks. The above dimensions were derived in the second stage of the analysis from in-depth interviews with key participants and detailed offline analysis of the observed networks.

The classification approach generates twenty four types of clothing networks in which Sri Lankan apparel manufacturers operate, as shown in Table 1. Existing classifications in the literature would typically place all of these network structures in a single category (e.g. 'virtual networks', Cravens et al 1996 [4]; 'flexible networks' by Cravens et al in 1996 [4] and by Ernst \& Kamrad in 2000 [6]; 'responsive networks' by Lee in 2002 [18]; 'dominated networks' by Verwaal \& Hesselmas in 2004 [29]; 'dynamic/high degree of focal firm influence' by Harland et al in 2001 [14]). The identification of twenty four types of clothing supply networks provides clearer and deeper insights and understanding on network structure and operation. 
Table 1. Clothing Supply Network Classification

\begin{tabular}{|c|c|c|c|c|c|c|c|}
\hline & \multicolumn{3}{|c|}{ Work directly with the manufacturers } & \multicolumn{3}{|c|}{ Work with the manufacturers via an agent } \\
\hline & & $\begin{array}{c}\text { Retailer } \\
\text { Sourcing }\end{array}$ & $\begin{array}{l}\text { Manufac- } \\
\text { turer } \\
\text { Sourcing }\end{array}$ & $\begin{array}{l}\text { Collaborative } \\
\text { Sourcing }\end{array}$ & $\begin{array}{c}\text { Retailer } \\
\text { Sourcing }\end{array}$ & $\begin{array}{c}\text { Manufacturer } \\
\text { Sourcing }\end{array}$ & $\begin{array}{c}\text { Collaborative } \\
\text { Sourcing }\end{array}$ \\
\hline \multirow[t]{2}{*}{ 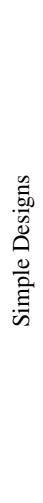 } & $\underset{\Xi}{\overparen{a}}$ & $\frac{\text { Type } 1}{\text { C20NW1 }}$ & $\begin{array}{l}\text { Type 2 } \\
\text { C21NW1 } \\
\text { C28NW3 }\end{array}$ & $\begin{array}{l}\text { Type } 3 \\
\text { C4NW3 } \\
\text { C4NW4 }\end{array}$ & $\begin{array}{l}\text { Type 4 } \\
\text { C4NW2A } \\
\text { C12NW1 } \\
\text { C25NW1 } \\
\text { C29NW1 } \\
\text { C13NW1 } \\
\text { C14NW1 } \\
\text { C26NW1 } \\
\text { C28NW1 } \\
\text { C19NW1 } \\
\text { C19NW2 }\end{array}$ & $\begin{array}{l}\text { Type 5 } \\
\text { C25NW3 } \\
\text { C29NW1 } \\
\text { C26NW3 } \\
\text { C28NW2 }\end{array}$ & Type 6 \\
\hline & $\frac{\overleftarrow{o}}{\mathrm{~g}}$ & $\begin{array}{l}\text { Type } 7 \\
\text { C6NW2 } \\
\text { C7NW3 }\end{array}$ & $\begin{array}{l}\text { Type } 8 \\
\text { C7NW1 } \\
\text { C17NW1 } \\
\text { C17NW4 } \\
\text { C24NW2 }\end{array}$ & $\begin{array}{l}\text { Type 9 } \\
\text { C1N4 } \\
\text { C8NW3 } \\
\text { C6NW2 } \\
\text { C17NW5 } \\
\text { C8NW1 } \\
\text { C8NW2 }\end{array}$ & $\frac{\text { Type } 10}{\text { C1N2 }}$ & $\begin{array}{l}\text { Type 11 } \\
\text { C4NW2B } \\
\text { C22NW1A } \\
\text { C24NW2 } \\
\text { C26NW2 }\end{array}$ & $\frac{\text { Type } 12}{\text { C1N3 }}$ \\
\hline \multirow[t]{2}{*}{ 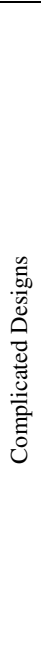 } & $\underset{\Xi}{\overparen{a}}$ & $\begin{array}{l}\text { Type 13 } \\
\text { C2N2 } \\
\text { C11NW1 } \\
\text { C27NW1 }\end{array}$ & $\begin{array}{l}\text { Type 14 } \\
\text { C3NW1 } \\
\text { C21NW1 } \\
\text { C27NW1 } \\
\text { C28NW3 }\end{array}$ & $\frac{\text { Type } 15}{\mathrm{C} 23 \mathrm{NW} 2}$ & $\begin{array}{l}\text { Type 16 } \\
\text { C29NW1 } \\
\text { C7NW2A } \\
\text { C14NW1 } \\
\text { C26NW1 } \\
\text { C1N1 } \\
\text { C15NW2A } \\
\text { C16NW1 } \\
\text { C27NW1 } \\
\text { C2N1 } \\
\text { C17NW2 } \\
\text { C18NW1B } \\
\text { C28NW1 } \\
\text { C4NW2A } \\
\text { C19NW1 } \\
\text { C19NW2 } \\
\text { C6NW1 } \\
\text { C22NW1B } \\
\text { C25NW1 }\end{array}$ & $\begin{array}{l}\text { Type 17 } \\
\text { C25NW3 } \\
\text { C29NW1 } \\
\text { C26NW3 } \\
\text { C27NW1 } \\
\text { C28NW2 } \\
\text { C7NW2B }\end{array}$ & $\begin{array}{l}\text { Type 18 } \\
\text { C6NW1 } \\
\text { C9NW1 } \\
\text { C15NW1A } \\
\text { C23NW1 }\end{array}$ \\
\hline & $\frac{\nwarrow}{2}$ & $\begin{array}{l}\text { Type 19 } \\
\text { C7NW3 } \\
\text { C16NW2 }\end{array}$ & $\begin{array}{l}\text { Type 20 } \\
\text { C10NW1 } \\
\text { C18NW2 } \\
\text { C24NW2 }\end{array}$ & $\begin{array}{l}\text { Type 21 } \\
\text { C8NW1 } \\
\text { C8NW2 } \\
\text { C8NW3 }\end{array}$ & $\begin{array}{l}\text { Type 22 } \\
\text { C15NW2B } \\
\text { C18NW1A } \\
\text { C22NW3 }\end{array}$ & $\begin{array}{l}\text { Type 23 } \\
\text { C10NW2 } \\
\text { C24NW1 } \\
\text { C25NW2 } \\
\text { C26NW2 }\end{array}$ & $\begin{array}{l}\text { Type 24 } \\
\text { C15NW1B } \\
\text { C17NW3 } \\
\text { C18NW3 }\end{array}$ \\
\hline
\end{tabular}

Note: The codes refer to supply networks in which apparel manufacturers operate. Identification codes are given for twenty nine companies although thirty companies have been studied. That is because $\mathrm{C} 3 \mathrm{NW}$ represents two selected companies.

A significant finding is that apparel manufacturers frequently operate within more than one type of supply network. For instance company 1 operates in four types of supply networks, namely type 16 , type 10 , type 12 , type 9 . Also in many cases, the same network physical structures have been shown to operate under different policies 
and hence are classified differently. For instance, C6NMW2, C28NW3, C24NW2, C27NW1. In most of the cases, the same physical network has been noted in two different types of network categories as it produces both complicated and simple designs for the same retailer under the same practices (e.g. C6NW2, C8NW1). Some networks appear in more than two categories (e.g. C24NW1, C27NW1) as they deal directly and indirectly with different retailers and produce garments both with and without embellishments for different retailers. Also control of fabric sourcing may vary between retailers and manufactures in some cases.

From the in-depth interviews with strategic level managers, the different motives and goals of retailers dictate how their supply networks are coordinated and managed. Consequently, major apparel manufacturers have to operate within different types of networks simultaneously, given that they may deal with different retailers and brand owners. This study shows how the different goals of the retailers result in different supply networks being developed and operated differently.

Two contributions are derived from this study. Firstly, different types of supply network structures operating in the international clothing industry are identified. These different types of network can be identified specifically by considering the four dimensions discussed above instead of considering only two dimensions used by previously reported generic supply network classifications. Secondly, it is clear that different types of network are governed by the different goals of the retailers in the clothing industry. Discussion on how such goals influence the development and management of supply networks has further added to the contribution.

We believe the study reported here and the classification developed has relevance for network design, management and improvement. Retailers need to understand the pressures being placed on their supply networks and how best to optimise performance for different classes of garments and different types of demand. Suppliers need to understand the strategies and policies of different retailers and how they can best position themselves to supply different retailer customers.

\section{Conclusions}

The design, operation and control of supply networks have become very important in many globally dispersed industries. The apparel industry is one of the most globalized and dynamic industries in the world and thus the structure, operation and control of its supply networks are important to investigate.

In this paper the nature of global supply networks in clothing has been discussed. The literature on supply network classification is limited in providing detailed understanding or insights on the structure and operation of such networks. The significance of retailers and their influencing power on the development and operation of global clothing supply networks has been noted. Due to the limitations in existing generic classifications, a new classification of clothing supply networks has been presented using evidence from a large scale study. This will be subjected to further analysis and development. The study here provides much potential for further research. In particular, the concepts and classification presented should provide valuable lines of enquiry for supply networks in other globally dispersed industries. 


\section{References}

1. Audet, D.: Smooth as silk? A first look at the post MFA textiles and Clothing landscape. Journal of International Economic Law 10(2), 267-284 (2007)

2. CBARSL - Central Bank Annual Report Sri Lanka, several issues

3. Christopher, M.: Logistics and Supply Chain Management: Creating Value-Adding Networks, 3rd edn. Prentice Hall, Englewood Cliffs (2005)

4. Cravens, D.W., Piercy, N.F., Shipp, S.H.: New Organizational Forms for Competing in Highly Dynamic Environments: the Network Paradigm. British Journal of Management 7, 203-218 (1996)

5. EMCC - European Monitoring Centre on Change: Trends and drivers of change in the European textiles and clothing sector: mapping report. European Foundation for the Improvement of Living and Working Conditions Report (google accessed on December 18, 2008)

6. Ernst, R., Kamrad, B.: Evaluation of Supply Chain Structures Through Modularization and Postponement. European Journal of Operational Research 124, 495-510 (2000)

7. Ferdows, K., Lewis, M.A., Machuca, J.A.D.: Rapid-fire Fulfilment. Harvard Business Review, 104-110 (2004)

8. Garavelli, A.C.: Flexibility Configurations for the Supply Chain Management. International Journal of Production Economics 85, 141-153 (2003)

9. Gereffi, G.: International Trade and Industrial Upgrading in the Apparel Commodity Chain. Journal of International Economics 48(1), 37-70 (1999)

10. Grandori, A., Soda, G.: Iner-Firm Networks: Antecedents, Mechanisms and Forms. Organization Studies 16(2), 183-214 (1995)

11. Harland, C.M.: Supply Chain Management Relationships, Chains and Networks. British Journal of Management 7, S63-S81 (1996) (special issue)

12. Harland, C.M., Knight, L.A.: Supply Network Strategy: Role and Competence Requirements. Int. Journal of Operations and Production Management 27(4), 476-489 (2001)

13. Harland, C., Zheng, J., Johnsen, T., Lamming, R.: A Conceptual Model for Researching the Creation and Operation of Supply Networks. British Journal of Management 15, 1-21 (2004)

14. Harland, C.M., Lamming, R.C., Zheng, J., Johnsen, T.E.: A Taxonomy of Supply Networks. Journal of Supply Chain Management 37(7), 21-27 (Fall 2001)

15. Hinterhuber, H.H., Levin, B.M.: Strategic Networks - The Organization of the Future. Long Range Planning 27(3), 43-53 (1994)

16. Hunter, A., King, R., Lowson, R.H.: The Textile/Clothing Pipeline and Quick Response Management, The Textile Institute (2002)

17. Lamming, R., Johnson, T., Zheng, J., Harland, C.: An Initial Classification of Supply Networks. Int. Journal of Operations and Production Management 20(6), 675-691 (2000)

18. Lee, H.L.: Aligning Supply Chain Strategies with Product Uncertainties. California Management Review Reprint Series 44(6), 106-119 (2002)

19. MacCarthy, B.L., Jayarathne, A.: Fast Fashion: Achieving Global Quick Response (GQR) in the Internationally Dispersed Clothing Industry. In: Cheng, E., Choi, J. (eds.) Springer Handbook on Innovative Quick Response Programs in Logistics and Supply Chain Management, ch. 3. Springer, Heidelberg (2010)

20. Martin, M.F.: US clothing and textile trade with china and the world: trends since the end of quotas. CRS report for congress, A report prepared for members and committees of congress on July 10 2007, Order Code RL34106 (2007), http: / /www. fas.org/ sgp/crs/row/RL34106.pdf (accessed October 18, 2008) 
21. Nassimbeni, G.: Network Structures and Co-ordination Mechanisms: A taxonomy. International Journal of Operations and Production Management 18(6), 538-554 (1998)

22. Robertson, P.L., Langlois, R.N.: Innovation, networks, and vertical integration. Research Policy 24, 543-562 (1995)

23. Rosenfeld, S.A.: Does Cooperation Enhance Competitiveness? Assessing the Impacts of Inter-Firm Collaboration. Research Policy 25, 247-263 (1996)

24. Sen, A.: The US Fashion Industry: A Supply Chain Review. International Journal of Production Economics 114(2), 571-593 (2008)

25. Tokatli, N.: Global Sourcing: Insights from the Global Clothing Industry-The Case of Zara, A Fast Fashion Retailer. Journal of Economic Geography (Advance Access Published in October 23, 2007)

26. Tyler, D., Heeley, J., Bhamra, T.: Supply Chain Influences on New Product Development in Fashion Clothing. Journal of Fashion Marketing and Management 10(3), 316-328 (2006)

27. UNCTAD Current Studies on FDI and Development: TNCs and the Removal of Textiles and Clothing Quotas, The United Nations (2005), http://www.unctad.org/ en/docs/iteiia20051_en.pdf

28. US department of labour, http://www.bls.gov (accessed on March 15, 2010)

29. Verwaal, E., Hesselmans, M.: Drivers of Supply Network Governance: An Explorative Study of the Dutch Chemical Industry. European Management Journal 22(4), 442-451 (2004)

30. Wadhwa, S., Saxenay, A., Chanz, F.T.S.: Framework for Flexibility in dynamic supply chain management. International Journal of Production Research 46(6), 1373-1404 (2008) 